\title{
Long-term mood/antidepressant effects of quetiapine extended-release formulation: an open-label, non-controlled extension study in Japanese patients with bipolar depression
}

Shigenobu Kanba ${ }^{1}$, Mitsukuni Murasaki ${ }^{2}$, Tsukasa Koyama ${ }^{3}$, Masahiro Takeuchi ${ }^{4}$, Yuriko Shimizu ${ }^{5}$, Eri Arita ${ }^{5}$, Kentaro Kuroishi ${ }^{6}$, Masahiro Takeuchi ${ }^{7}$ and Shinya Kamei ${ }^{5^{*}}$

\begin{abstract}
Background: In an 8-week, randomized, placebo-controlled, double-blind study, an extended-release formulation of quetiapine, quetiapine XR, demonstrated efficacy and safety in Japanese patients with bipolar depression. Bipolar disorder is a chronic disease requiring continuous treatment.

Methods: This was a long-term (52-week), open-label, non-controlled extension study to evaluate the long-term safety and efficacy of quetiapine XR in Japanese patients with bipolar depression who had previously completed the initial 8-week double-blind study. Efficacy was determined by the Montgomery-Åsberg Depression Rating Scale (MADRS), Hamilton Depression Scale 17-item (HAM-D 17), and Clinical Global Impressions-Bipolar scale (CGI-BP). Safety evaluations included analysis of adverse events, clinical laboratory measures, vital signs, Drug-induced Extrapyramidal Symptoms Scale, Young Mania Rating Scale, and the Columbia Suicide Severity Rating Scale.

Results: The mean (SD) MADRS total score decreased from 30.9 (6.9) at baseline to 16.1 (10.6) at week 8, and eventually to 9.1 (8.7) at week 52. The sustained efficacy of quetiapine XR treatment was also shown using HAM-D 17 total scores, CGI-BP-Severity and Change evaluations. The most common adverse events were somnolence, nasopharyngitis, and thirst. Long-term treatment with quetiapine XR caused no substantial changes in the safety profiles, including clinical laboratory parameters, and no new safety concerns were identified.
\end{abstract}

Conclusions: The efficacy of quetiapine XR was sustained long-term and no new safety concerns were identified in Japanese patients with bipolar depression.

Trial registration: ClinicalTrials.gov Registration: NCT01725308. Date of registration; 12th November 2012 (retrospectively registered).

Keywords: Quetiapine XR, Bipolar disorder, Depression

\footnotetext{
* Correspondence: shinya.kamei@astellas.com

${ }^{5}$ Japan/Asia Clinical Development 2, Astellas Pharma Inc.; 2-5-1

Nihonbashi-Honcho, Chuo-ku, Tokyo 103-8411, Japan

Full list of author information is available at the end of the article
}

(c) The Author(s). 2019 Open Access This article is distributed under the terms of the Creative Commons Attribution 4.0 International License (http://creativecommons.org/licenses/by/4.0/), which permits unrestricted use, distribution, and reproduction in any medium, provided you give appropriate credit to the original author(s) and the source, provide a link to the Creative Commons license, and indicate if changes were made. The Creative Commons Public Domain Dedication waiver (http://creativecommons.org/publicdomain/zero/1.0/) applies to the data made available in this article, unless otherwise stated. 


\section{Background}

Bipolar disorder is a chronic mood disorder characterized by recurrent and cyclical emotional disturbances. Bipolar I disorder is a syndrome involving at least one manic episode, while bipolar II disorder involves at least one hypomanic episode and one major depressive episode [1]. According to a global survey, the lifetime prevalences of bipolar I disorder and bipolar II disorder are 0.6 and $0.4 \%$, respectively [2].

Major treatment guidelines for bipolar disorder recommend mood stabilizers and antipsychotics as first-line therapy for the treatment of bipolar depression, and quetiapine monotherapy is recommended as one of the first-line treatments for bipolar depression [3-6].

Several clinical studies have demonstrated the efficacy of immediate-release (IR) and extended-release formulations of the atypical antipsychotic quetiapine to reduce depressive symptoms in bipolar disorder [7-9]. We recently showed in an 8-week, placebo-controlled, doubleblind, parallel-group comparative study that once-daily monotherapy with $300 \mathrm{mg} /$ day quetiapine XR is an effective and well-tolerated treatment for Japanese patients with bipolar depression [10].

Bipolar disorder is a long-term illness and patients with bipolar I disorder and bipolar II disorder have been shown to exhibit symptoms 47.3 and $53.9 \%$ of the time, respectively $[11,12]$. Research has also shown that depressive symptoms can be approximately three times (31.9\% versus $8.9 \%$ ) and 39 times (50.3\% versus $1.3 \%$ ) longer than manic symptoms in bipolar I disorder and hypomanic symptoms in bipolar II disorder, respectively $[11,12]$. Therefore, understanding the long-term efficacy and safety of the treatment in such patients is critical to further optimize the long-term management of bipolar depression with quetiapine.

The utility of long-term quetiapine treatment for patients with bipolar depression has been investigated outside Japan, and was well tolerated while showing significant reduction in the recurrence of depressive episodes [13], but it has not yet been studied in Japanese patients with bipolar depression. Therefore, the present study, an open-label, non-controlled extension study, aimed to investigate the safety and efficacy of long-term quetiapine XR treatment in Japanese patients with bipolar depression who completed the initial 8-week, doubleblind study.

\section{Methods}

\section{Study design}

This was a multicenter, open-label, non-controlled extension study to determine the long-term safety and efficacy of quetiapine XR therapy across 98 sites. This study followed on from an 8-week placebocontrolled, double-blind, parallel-group comparative study [10] conducted in Japanese patients with bipolar depression.

After completion of the initial 8-week double-blind study, patients who met the transition criteria were transferred to a 44-week long-term extension period of the study. The extension period commenced with a 4week transition period (week 8 to week 12) followed by a 4-week dose-adjustment period (week 12 to week 16), and a continued treatment period for 36 weeks (week 16 to week 52) under open-label conditions (Fig. 1). In the initial 8-week study, patients were randomized to receive $150 \mathrm{mg} /$ day quetiapine $\mathrm{XR}, 300 \mathrm{mg} /$ day quetiapine $\mathrm{XR}$, or placebo. The randomization to $150 \mathrm{mg}$ /day quetiapine $\mathrm{XR}$, however, was discontinued due to the difficulty of recruiting patients after consultation with the Pharmaceuticals and Medical Devices Agency.

\section{Patient population}

In the initial 8-week double-blind study, patients were eligible if they were aged between 20 and 64 years; had a documented clinical diagnosis as per the Diagnostic and Statistical Manual of Mental Disorders, 4th Edition, Text Revision (DSM-IV-TR) [14] criteria for bipolar I disorder or bipolar II disorder, a recent depressive episode (296.50-296.54 or 296.89) as confirmed by the MiniInternational Neuropsychiatric Interview (M.I.N.I.); HAM-D ${ }_{17}$ total score $\geq 20$ points and HAM-D $D_{17}$ depressed mood score $\geq 2$ points; and a negative pregnancy test result in female patients of childbearing potential.

Patients were not eligible if the following criteria were met: concurrent or previous history of DSM-IV-TR Axis I disorders, except bipolar disorder, within 6 months prior to informed consent; a concurrent DSM-IV-TR Axis II disorder that greatly affected the patient's current mental status; a Young Mania Rating Scale (YMRS) total score of $\geq 13$ points; $\geq 9$ mood episodes within 12 months prior to informed consent; no response to at least two different antidepressants for > 6 weeks; history of substance or alcohol abuse; HAM-D $\mathrm{D}_{17}$ suicide score of $\geq 3$ points, or a history of suicide attempts within 6 months prior to informed consent.

The criteria for transition from the initial 8-week double-blind phase to the 44-week extension phase included written informed consent, negative pregnancy test, judged to be able to follow patient requirements, and the absence of any safety issues as determined by the investigators.

\section{Study medication}

Patients who transitioned to the 4-week transition period (week 8 to week 12) continued the same dose of quetiapine $\mathrm{XR}$ as in the initial 8-week study (Fig. 1). After the transition period, all patients entered a 4-week 


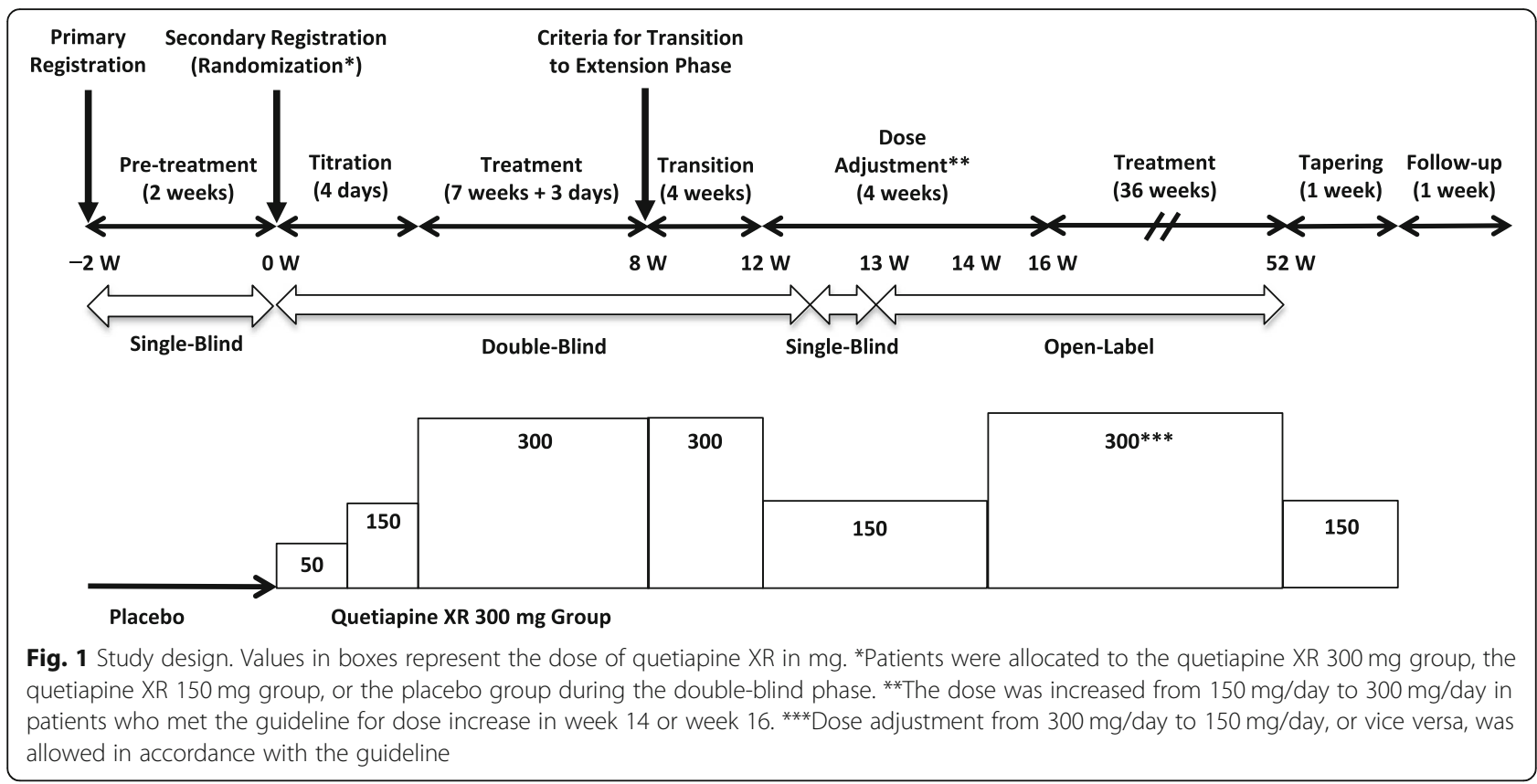

dose-adjustment period (week 12 to week 16), and the dose was increased from $150 \mathrm{mg} /$ day to $300 \mathrm{mg} /$ day in patients who met the guideline for dose increase in week 14 or 16.

The guideline for dose increase was as follows: no moderate or severe drug-related adverse event occurred until the assessment point, and a Clinical Global Impressions-Bipolar-Change (CGI-BP-C) (Depression) rating of "no change" to "very much worse" (week 14 only). In principle, the target dose was $300 \mathrm{mg} /$ day; however, if a moderate or severe drug-related adverse event occurred after the dose increase, a dose reduction to $150 \mathrm{mg} /$ day was allowed. Dose adjustment from $150 \mathrm{mg} /$ day to $300 \mathrm{mg} /$ day, or vice versa, was allowed multiple times in accordance with the guidelines and at the discretion of the investigators. During the tapering period, quetiapine XR dosage was tapered to $150 \mathrm{mg} /$ day for 1 week in patients who were administered quetiapine XR $300 \mathrm{mg} /$ day at the end of treatment period, and patients were followed-up for an additional week (Fig. 1).

\section{Prior and concomitant medications}

The following concomitant drugs were not permitted except for those specified as conditionally permitted (see next paragraph): mood stabilizers (lithium carbonate, sodium valproate), lamotrigine, antipsychotics, antidepressants, antiepileptics, antianxiety agents, hypnotics, sedatives, cytochrome P450 3A4 (CYP3A4) inhibitors or inducers, monoamine oxidase (MAO) inhibitors, psychostimulants, antiparkinsonian agents, cerebral ameliorators, antidementia agents, anorectics, and adrenaline.
Conditionally allowed concomitant drugs included lorazepam (if it had been used $\geq 14$ days before the primary registration), only one hypnotic (zopiclone, triazolam, or eszopiclone, which had been used $\geq 14$ days before the primary registration), and only one anticholinergic (if it had been indicated for the treatment of extrapyramidal symptoms).

\section{Efficacy evaluations}

In the combined analysis of the double-blind treatment phase and the extension phase, the baseline was defined as the start of the double-blind treatment period (week $0)$.

Patients whose MADRS total score decreased by $50 \%$ or more from baseline were defined as patients with MADRS response, and patients whose MADRS total scores were $\leq 12$ were defined as patients with MADRS remission. HAM- $\mathrm{D}_{17}$, Clinical Global ImpressionsBipolar-Severity of illness (CGI-BP-S) score and CGIBP-C score were also assessed [15]. Patients who had a CGI-BP-C response were defined as "much improved" or "very much improved".

Clinical assessments of MADRS, CGI-BP-S, and CGI-BP-C were conducted at weeks 10 and 12 during the transition period, weeks 13 (MADRS only), 14, and 16 during the dose-adjustment period, and weeks $18,20,24,28,32,36,40,44,48,52$, and at follow-up (week 54). Clinical assessments of HAM-D ${ }_{17}$ were conducted at weeks 10 and 12 during the transition period, weeks 14 and 16 during the dose-adjustment period, and weeks $20,28,36,44,52$, and at follow-up (week 54). 


\section{Safety and tolerability}

Safety variables were assessed during the quetiapine XR treatment period and included adverse events (AEs), laboratory assessments (blood biochemistry, hematology, and urinalysis), body weight, vital signs (blood pressure and pulse rate), 12-lead electrocardiography (ECG) with QT interval and corrected (QTc) using Fridericia's formula, Drug-Induced Extrapyramidal Symptoms Scale (DIEPSS), YMRS, and the Columbia Suicide Severity Rating Scale (C-SSRS).

\section{Statistical analyses}

The target sample size was at least 100 patients treated for a period of 1 year [16].

The full analysis set included all patients who received at least one dose of quetiapine XR from commencement of the initial 8-week double-blind study. The safety analysis set included safety data from both the double-blind phase and extension phase combined, except for patients who received only placebo. For each evaluation, the measured values at each time point and summary statistics (mean, standard deviation [SD]) of changes were calculated.

Regarding the efficacy and safety assessment of the quetiapine XR $150 \mathrm{mg}$ group, assignment of patients to this group was discontinued; therefore, data for this group are not presented. In addition, patients allocated to the placebo group did not receive quetiapine XR for 52 weeks, and therefore, efficacy and safety data are not shown. Therefore, the data shown here represent patients allocated to the quetiapine XR $300 \mathrm{mg}$ group during the initial 8-week double-blind phase.

\section{Results}

\section{Patient and disposition}

The patient characteristics of the initial 8-week double-blind study were described previously [10]. Of the 179 patients receiving $300 \mathrm{mg}$ quetiapine $\mathrm{XR}$ in the previous study, 130 patients transitioned into this extension phase. Of these 130 patients, 74 patients completed the extension phase (Fig. 2). The demographic and clinical characteristics, and the baseline values for MADRS and HAM-D ${ }_{17}$ evaluations are shown in Table 1.

\section{Efficacy \\ MADRS}

The mean (SD) MADRS total score in the observed cases (OC) decreased from 30.9 (6.9) at baseline to 16.1 (10.6) at week 8 , and the decrease continued thereafter to 9.1 (8.7) at week 52 (Fig. 3). The mean (SD) change from baseline to the end of treatment was - 15.2 (12.2).

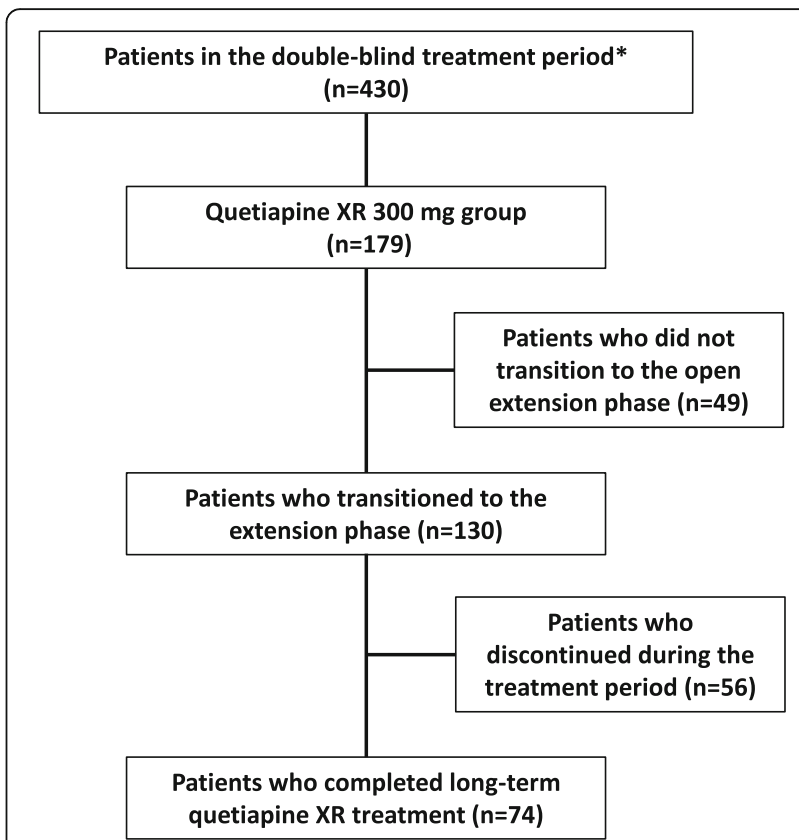

Fig. 2 Patient disposition. *The study drug was administered to 179 patients in the quetiapine XR $300 \mathrm{mg}$ group, 74 patients in the quetiapine XR $150 \mathrm{mg}$ group, and 177 patients in the placebo group

The proportion of patients with a MADRS response or MADRS remission at the end of treatment is shown in Table 2. The proportion of patients with a MADRS response (OC) increased over time until week $12(56.7 \%)$, and subsequently tended to increase gradually until week $52(77.0 \%)$. At the end of the treatment, it was $49.7 \%$. The proportion of patients with a MADRS remission (OC) increased over time until week 18 (59.1\%), and subsequently remained within a range of $55.7 \%$ (week 20) to $68.9 \%$ (week 52) . At the end of the treatment, it was $45.8 \%$.

Subgroup analyses of patients stratified by sex, age, diagnosis (bipolar I or bipolar II disorder), baseline MADRS total score, and baseline HAM- $\mathrm{D}_{17}$ total score were performed for the change from baseline in MADRS total score, revealing no clear differences between subgroups based on sex, age, and diagnosis. In the subgroups stratified by the baseline MADRS total score and the baseline HAM- $\mathrm{D}_{17}$ total score, the change from baseline in MADRS total score tended to be greater in the subgroup with the more severe symptoms.

\section{$H A M-D_{17}$}

The mean (SD) HAM- $\mathrm{D}_{17}$ total score (OC) decreased from 23.0 (3.0) at baseline to 11.5 (6.6) at week 8, and this decrease continued thereafter to $7.1(6.1)$ at week 52. The mean (SD) change from baseline at the end of the treatment was $-11.6(8.3)$. 
Table 1 Demographic, clinical characteristics, and baseline values for MADRS and HAM-D 17 evaluations

\begin{tabular}{lll}
\hline Variable & & Quetiapine XR $(n=179)$ \\
\hline Age (Years), mean (SD) & Male & $38.1(11.2)$ \\
Sex & Female & $86(48.0 \%)$ \\
& Bipolar I Disorder & $93(52.0 \%)$ \\
Diagnosis & Bipolar II Disorder & $51(28.5 \%)$ \\
& $\geq 4$ & $128(71.5 \%)$ \\
Number of Mood Episodes in the Past 12 Months & & $14(7.8 \%)$ \\
MADRS Total Score, mean (SD) & & $30.9(6.9)$ \\
HAM-D 17 Total Score, mean (SD) & & $23.0(3.0)$
\end{tabular}

$\mathrm{n}(\%)$

MADRS Montgomery-Åsberg Depression Rating Scale, $H A M-D_{17}$ Hamilton Depression Scale Item-17

\section{CGI-BP-S}

The mean (SD) CGI-BP-S (Overall bipolar illness) score (OC) decreased from 4.4 (0.8) at baseline to 3.0 (1.1) at week 8 , and that at week 52 was 2.1 (1.1). The mean (SD) change from baseline at the end of treatment was -1.5 (1.5). The mean (SD) CGI-BP-S (Depression) decreased (OC) from $4.5(0.7)$ at baseline to 3.0 (1.1) at week 8, and that at week 52 was 2.1 (1.1). The mean (SD) change in CGI-BP-S (Depression) score from baseline at the end of treatment was - $1.6(1.5)$.

\section{CGI-BP-C}

The proportion of CGI-BP-C (Overall bipolar illness and Depression) responders at the end of treatment is described in Table 2. The proportion of patients with a CGI-BP-C (Overall bipolar illness) response (OC) increased over time until week 14 (62.7\%), and subsequently remained within a range of $59.8 \%$ (week 16) to $78.4 \%$ (week 52). At the end of treatment, it was 51.4\%. The proportion of patients with a CGI-BP-C (Depression) response $(\mathrm{OC})$ also increased over time until week

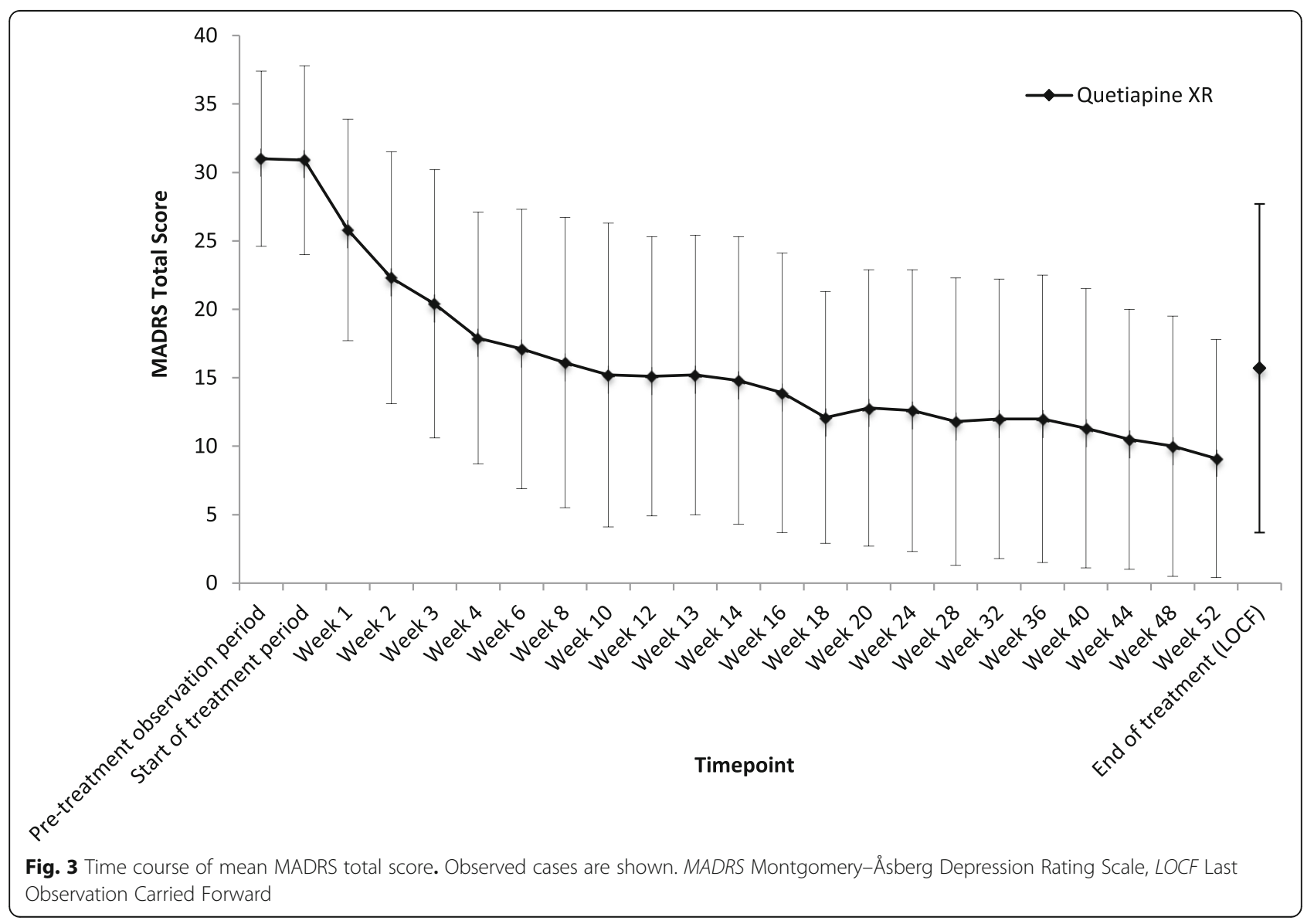


Table 2 MADRS response, MADRS remission, and CGI-BP-C response at the end of treatment

\begin{tabular}{lll}
\hline & & Quetiapine XR $(n=179)$ \\
\hline Patients with a Response Based on MADRS Total Score & & $89(49.7 \%)$ \\
Patients with a Remission Based on MADRS Total Score & & $82(45.8 \%)$ \\
Patients with a Response Based on CGI-BP-C Score & Overall Bipolar Illness & $92(51.4 \%)$ \\
& Depression & $95(53.1 \%)$ \\
& Mania & $0(0.0 \%)$ \\
\hline
\end{tabular}

$\mathrm{n}(\%)$

MADRS Montgomery-Åsberg Depression Rating Scale, CGI-BP-C Clinical Global Impressions-Bipolar-Change

$14(62.7 \%)$, and remained within a range of $59.8 \%$ (week 16) to $78.4 \%$ (week 52 ). At the end of treatment, it was $53.1 \%$.

\section{Safety and tolerability Adverse events}

Table 3 provides a summary of AEs. The incidence of AEs was $95.5 \%$ (171/179 patients), and the incidence of drug-related AEs was $88.8 \%$ (159/179 patients). No deaths were reported, and serious adverse events (SAEs) were reported in five patients (spinal compression fracture, mania, appendicitis, and atrial flutter in one patient each, asthma and altered state of consciousness in one patient). The incidence of AEs leading to discontinuation was $28.5 \%$ (51/179 patients). Most of the AEs were mild or moderate in severity; three severe AEs occurred in two patients (mania in one patient and asthma and altered state of consciousness in one patient).

Additional file 1 Table S1 summarizes AEs that occurred in $>5 \%$ of patients during this study. The most common AE was somnolence (54.2\%), followed by nasopharyngitis $(32.4 \%)$, and thirst $(28.5 \%)$. AEs with an incidence of $10 \%$ or higher were malaise (12.3\%), constipation (11.7\%), blood prolactin increased (11.7\%), akathisia (11.7\%), and weight increased (10.6\%).

Regarding the period during which first onset of AEs was observed, the incidence of AEs was the highest (55.9\%) during the early stage of treatment (Day $1-7$ ), with the incidence in subsequent periods ranging from 0 to $10.7 \%$.

\section{AEs related to manic and hypomanic symptoms}

The incidence of AEs related to manic or hypomanic symptoms was $3.9 \%$ (7/179 patients); these were hypomania $(2.8 \%, 5 / 179$ patients), bipolar I disorder $(0.6 \%, 1 /$ 179 patients), and mania (0.6\%, $1 / 179$ patients). Manic symptoms, as assessed by the mean (SD) YMRS total score, were 2.1 (1.7) at baseline and 1.7 (4.3) at the end of treatment, showing no worsening in the mean YMRS total score.

\section{AEs related to extrapyramidal symptoms}

The incidence of AEs related to extrapyramidal symptoms was $19.0 \%$ (34/179 patients). The most common AE was akathisia (11.7\%, 21/179 patients); however, there was little change in DIEPSS during the treatment period.

\section{AEs related to suicide}

The incidence of AEs related to suicide was 4.5\% (8/179 patients); these events included intentional self-injury (1.1\%, 2/179 patients), suicidal ideation (1.1\%, 2/179 patients), suicide attempt (1.1\%, 2/179 patients), and selfinjurious behavior (1.1\%, 2/179 patients).

\section{Withdrawal symptoms and rebound phenomenon}

To assess drug withdrawal syndrome, withdrawal symptoms were assessed among the AEs that occurred during the dose-tapering period and the follow-up period. The incidence of AEs was $13.6 \%$ (9/66 patients) in the dosetapering period and $18.8 \%$ (18/96 patients) in the follow-

Table 3 Summary of adverse events

\begin{tabular}{lll}
\hline & Quetiapine XR $(n=179)$ & Number of AEs \\
\cline { 2 - 3 } AEs & Number of Patients (\%) & 845 \\
Drug-related AEs & $171(95.5 \%)$ & 559 \\
Deaths & $159(88.8 \%)$ & - \\
SAEs & 0 & 6 \\
Drug-related SAEs & $5(2.8 \%)$ & 2 \\
AEs leading to discontinuation & $2(1.1 \%)$ & 64 \\
Drug-related AEs leading to discontinuation & $51(28.5 \%)$ & 49
\end{tabular}

$A E s$ adverse events, SAEs serious adverse events 
up period. Of these AEs, drug withdrawal syndrome was reported in two patients $(2.1 \%)$ in the follow-up period, and withdrawal syndrome was reported in one patient (1.5\%) in the dose-tapering period and in two patients (2.1\%) in the follow-up period. These AEs resolved, except for withdrawal syndrome in one patient.

Regarding rebound phenomenon, there was no obvious worsening observed in the follow-up period in each assessment of depression symptoms, including MADRS.

\section{Clinical laboratory evaluations}

Changes in clinical laboratory evaluations are presented in Table 4. The incidence of weight increased was $10.6 \%$, and the mean (SD) change from baseline in body weight at the end of treatment was $1.02(3.99) \mathrm{kg}$. No particularly significant changes in the mean values were found for any of the hematological parameters. For blood biochemistry parameters, the mean triglyceride levels tended to increase from baseline to the end of treatment $(128.2 \mathrm{mg} / \mathrm{dL}$ at baseline and $139.9 \mathrm{mg} / \mathrm{dL}$ at the end of treatment). There were no significant changes in the mean values for blood glucose, HbA1c, total cholesterol, and blood prolactin measures from baseline to the end of treatment.

The 12-lead ECG findings showed that four patients had clinically significant abnormalities as judged by an investigator. Of these patients, one patient had a clinically significant abnormality (atrial flutter) from week 8 through to week 28 that was assessed as a SAE and subsequently underwent catheter ablation. The mean change (SD) from baseline in QTc (Fridericia) was 1.9 (13.2) msec at the end of treatment, and none of the patients had QTc (Fridericia) exceeding $480 \mathrm{msec}$ at any assessment point.

\section{Discussion}

Previous long-term studies, EMBOLDEN I and II, have showed that quetiapine monotherapy in patients with bipolar depression was effective within 8 weeks, and the efficacy for 52 weeks as assessed by the change in MADRS total score $[13,17,18]$. In these studies, the risk of recurrence of a depressive relapse was significantly lower with quetiapine compared with placebo, which is suggestive of quetiapine's efficacy in both short- and long-term therapy in patients with bipolar depression. Moreover, these studies showed that quetiapine monotherapy has an acceptable safety and tolerability profile.

This open-label extension study evaluated the longterm safety and efficacy of quetiapine treatment in Japanese patients with bipolar depression who had completed the initial 8-week double-blind study [10]. During the acute treatment period, administration of $300 \mathrm{mg} /$ day quetiapine XR for 8 weeks resulted in a superior reduction from baseline in MADRS total score in comparison with placebo. For those patients that successfully transitioned to long-term treatment, the efficacy of quetiapine XR treatment was maintained as evidenced by rating MADRS, HAM-D 17 , CGI-BP-S, and CGI-BP-C in a patient population that included both bipolar I and bipolar II disorder diagnoses. Furthermore, there were no marked differences in the development of AEs after long-term quetiapine XR administration, and no new safety concerns in terms of laboratory values or vital signs. The number of patients whose dose of quetiapine XR was increased from $150 \mathrm{mg} /$ day to $300 \mathrm{mg} /$ day during the dose-adjustment period was 98 . Of these $98 \mathrm{pa}$ tients, 68 maintained a dose of $300 \mathrm{mg} /$ day for the rest of the extension phase, and quetiapine XR monotherapy for bipolar depression was well tolerated.

Changes of body weight, metabolic parameters, and blood prolactin levels are common after the administration of atypical antipsychotics [19-21]. In this study, long-term quetiapine XR treatment caused an increase in mean weight; however, this increase in weight did not cause patients to withdraw from the study. Blood glucose and HbA1c levels showed an increase; however, this

Table 4 Clinical laboratory evaluations

\begin{tabular}{llll}
\hline & Baseline & End of treatment & Change from baseline \\
\hline & Quetiapine XR & Quetiapine XR & Quetiapine XR \\
& Mean (SD) & Mean (SD) & Mean (SD) \\
Body weight (kg) & $63.15(13.71)$ & $64.26(13.67)$ & $1.02(3.99)$ \\
Blood glucose (mg/dL) & $98.5(14.2)$ & $100.3(16.4)$ & $2.1(18.4)$ \\
HbA1c (\%) & $5.05(0.27)$ & $5.09(0.31)$ & $0.04(0.23)$ \\
Total Cholesterol (mg/dL) & $191.0(35.6)$ & $193.7(38.3)$ & $3.2(29.3)$ \\
HDL-C (mg/dL) & $56.5(16.7)$ & $56.5(16.8)$ & $0.1(8.2)$ \\
LDL-C (mg/dL) & $115.4(32.0)$ & $115.8(33.2)$ & $0.6(24.1)$ \\
Triglycerides (mg/dL) & $128.2(80.1)$ & $139.9(116.6)$ & $11.8(90.2)$ \\
Prolactin (ng/mL) & $10.529(6.779)$ & $10.040(6.472)$ & $-0.458(7.002)$ \\
\hline
\end{tabular}

HbA1c Hemoglobin A1c, HDL-C High-density lipoprotein-cholesterol, LDL-C Low-density lipoprotein-cholesterol 
increase was not significant. Serum triglyceride levels also showed a tendency to increase. Mean increases in total cholesterol and triglycerides levels have previously been reported for both quetiapine and olanzapine, with regular monitoring of metabolic parameters recommended as routine clinical practice [22].

A number of typical and atypical antipsychotics have demonstrated induction of a sustained hyperprolactinemia above normal ranges [23]. However, quetiapine has previously been documented to decrease blood prolactin levels $[24,25]$. In this long-term study, there was no significant change in the mean change from baseline in blood prolactin levels.

The safety profile of quetiapine in patients with bipolar depression is well established in clinical trials $[7-9,13$, $17,18]$. In this extension study, no deaths were reported, and all AEs were mild to moderate in severity, except for three severe AEs. In this instance, quetiapine XR treatment in patients with severe AEs was discontinued, and most AEs were successfully resolved. Therefore, in summary, the safety results described here are in line with previous observations.

Patients with bipolar depression are vulnerable to drug-induced extrapyramidal symptoms with typical antipsychotic agents [26]. However, quetiapine is an atypical antipsychotic that comes with a lower risk for acute extrapyramidal symptoms [27], and this was confirmed in this study. The long-term administration of quetiapine XR monotherapy in patients with bipolar depression showed no particularly significant trends of drug-induced extrapyramidal symptoms as confirmed using DIEPSS.

Patients with bipolar depression are also vulnerable to treatment-induced manic switching, particularly in those treated with antidepressants monotherapy [28]. Quetiapine monotherapy reduces bipolar depressive symptoms in the absence of worsening mania symptoms, as evidenced in this study by the lack of worsening in the mean YMRS total score.

Drug-induced withdrawal syndrome and withdrawal syndrome was observed in some patients, but the incidence was not high, and, for the majority of those patients, AEs were resolved. Assessment of rebound phenomenon showed no obvious worsening in any of the efficacy variables during the post-treatment observation period, including MADRS analysis. Although depression and AEs related to suicide were reported during the dose-tapering period and the follow-up period, all of these AEs were non-serious and confirmed to have been resolved.

The present study has some limitations. The results of this long-term study include data on quetiapine XR treatment for 52 weeks. However, the initial 8-weekperiod was a double-blind study, and the remaining extension phase was an open-label study; therefore, the manner of blinding was different in different parts of this study. Furthermore, the study design was changed because allocation of patients to the quetiapine XR 150 mg group was discontinued during the double-blind phase. In addition, patients who were allocated to the placebo group in the double-blind study did not receive quetiapine XR for 52 weeks. Therefore, data from patients allocated to the quetiapine XR $300 \mathrm{mg}$ group in the double-blind study were used to show the long-term efficacy and safety of quetiapine XR for bipolar depression. Additionally, these findings in Japanese patients may not be generalizable to other populations.

\section{Conclusions}

This study was conducted to evaluate the efficacy and safety of quetiapine XR in Japanese patients with bipolar depression over a 44-week extension treatment period to an 8-week double-blind study. The long-term efficacy and safety of treatment with quetiapine XR in Japanese patients with bipolar depression were confirmed. The efficacy of quetiapine XR was sustained until week 52, which was the final assessment in the treatment period, for all the efficacy variables. AEs, including somnolence, thirst, and various other abnormal laboratory values, were observed; however, these safety profiles have already been confirmed in previous quetiapine XR trials. Therefore, no new safety concerns were found after long-term administration.

\section{Additional file}

Additional file 1: Table S1: Adverse events that occurred in $>5 \%$ of patients. (PDF $99 \mathrm{~kb}$ )

\section{Abbreviations}

CGI-BP-C: Clinical Global Impressions-Bipolar-Change; CGI-BP-S: Clinical Global Impressions-Bipolar-Severity of illness; C-SSRS: Columbia Suicide Severity Rating Scale; DIEPSS: Drug-induced extrapyramidal symptoms scale; DSM-IVTR: Diagnostic and Statistical Manual of Mental Disorders, 4th Edition, Text Revision; ECG: Electrocardiography; HAM-D 17 : Hamilton Depression Scale 17item; IR: Immediate Release; M.I.N.I: Mini-International Neuropsychiatric Interview; MADRS: Montgomery-Åsberg Depression Rating Scale; MAO: Monoamine oxidase; YMRS: Young Mania Rating Scale

\section{Acknowledgements \\ The authors would like to thank James Graham, PhD, and Wendy Brooks, PhD, of Edanz Medical Writing on behalf of inScience Communications, Springer Healthcare, for providing medical writing services.}

\section{Data sharing statement}

Access to anonymized individual participant level data collected during the study, in addition to supporting clinical documentation, is planned for studies conducted with approved product indications and formulations, as well as compounds terminated during development. Studies conducted with product indications or formulations that remain active in development are assessed after study completion to determine if Individual Participant Data can be shared. Conditions and exceptions are described under the Sponsor Specific Details for Astellas on https://www.clinicalstudydatarequest.com/. Study-related supporting documentation is redacted and provided if 
available, such as the protocol and amendments, statistical analysis plan and clinical study report. Access to participant level data is offered to researchers after publication of the primary manuscript (if applicable) and is available as long as Astellas has legal authority to provide the data. Researchers must submit a proposal to conduct a scientifically relevant analysis of the study data. The research proposal is reviewed by an Independent Research Panel. If the proposal is approved, access to the study data is provided in a secure data sharing environment after receipt of a signed Data Sharing Agreement.

\section{Authors' contributions}

All authors proposed key elements of study concept, reviewed the draft protocol, and made significant contributions to the design. KK analyzed the data, and all authors participated in evaluation and assessment of data. SK, as corresponding author, led an authors' meeting to determine the content of the manuscript and guided the overall writing process for this manuscript from start to finish. All authors were responsible for the interpretation of data and critically revised the manuscript. All authors take responsibility for the integrity of the work as a whole, and have given their approval for the final manuscript to be published.

\section{Funding}

This study was funded by Astellas Pharma Inc. Employees of Astellas Pharma who are listed as authors had roles in the writing of this manuscript, and in the study design, analysis and interpretation of data.

\section{Availability of data and materials}

The datasets used and/or analyzed during the current study are available on reasonable request from https://www.clinicalstudydatarequest.com/. The final report is available on the Astellas Clinical Study Results (ACSR) website: https://astellasclinicalstudyresults.com/hcp/compoundresult.aspx?PC=31

\section{Ethics approval and consent to participate}

The study was conducted in adherence to the ethical principles that are based on the Declaration of Helsinki, Good Clinical Practice, guidelines of the International Council for Harmonization of Technical Requirements for Pharmaceuticals for Human Use, and applicable laws and regulations. Patients provided written informed consent prior to commencement of the study. The following institutional review boards provided ethical approval for the study: Hokkaido University Hospital, Kyushu University Hospital, Akita City Hospital, Nanko Psychiatric Institute, Mito Medical Center, Seimou Hospital, Shoda Hospital, Adachi Kyosai Hospital, Nippon Medical School Chiba Hokusoh Hospital, Suzuki Hospital, Neuropsychiatric Research Institute, Showa University Karasuyama Hospital, Suzuki Internal Medicine and Cardiology, Akasaka Clinic, Mizuo Clinic, Himorogi Psychiatric Institute, Keihinchuo Clinic \& Hisamitsu Clinic \& Masabayashi Clinic, Tokyo-eki Centerbuilding Clinic, Eda Memorial Hospital, Kayaba-cho Dermatology, Minamitoyama Nakagawa Hospital, Japanese Red Cross Society Azumino Hospital, Aichi Medical Association, Yuge Hospital, Asakayama General Hospital, Kindai University Hospital, Kusatsu Hospital, Tokushima University Hospital, Omutachuo Hospital, Haradoi Hospital, Yokohama Minoru Clinic, University of the Ryukyus Hospital, Kurayoshi Hospital, Nishigahara Hospital, Arakaki Hospital, Hannan Hospital, Kagawa University Hospital, Yatsushiro-kousei Hospital, Tokyo Shinjuku Medical Center, Nagoya University Hospital, Oita University Hospital, Okayama University Hospital, Fujita Health University Hospital, Hiroshima University Hospital, Hospital of the University of Occupational and Environmental Health, Ashiribetsu Hospital, Riverside Clinic, Minami Sakai Hospital, Keio University Hospital, Tokyo Musashino Hospital, Mitsui Memorial Hospital, Brain Attack Center Ota Memorial Hospital, Hokkaido Study Group of Clinical Psychopharmacology, Okamoto Hospital, Center Hospital of the National Center for Global Health and Medicine, Ongata Hospital, Yamato Mental Medical Center, Sapporo City General Hospital, Hiro Clinic Omori, Japanese Red Cross Medical Center, Negishi Hospital, Nishi Hospital, and Kondou Hospital.

\section{Consent for publication}

Not applicable.

\section{Competing interests}

Specific and substantive relationships are as follows: Shigenobu Kanba declares honoraria from MSD K.K., Astellas Pharma Inc., Mochida Pharmaceutical Co., Ltd., Eisai Co., Ltd., Takeda Pharmaceutical Co., Ltd.,
Dainippon-Sumitomo Pharma Co. Ltd., Otsuka Pharmaceutical Co., Ltd., Taisho-Toyama Pharmaceutical Co. Ltd., Janssen Pharmaceutical K.K., Meiji Seika Pharma Co. Ltd., Yoshitomiyakuhin Co., Nippon Chemiphar Co. Ltd., Daiichi Sankyo Co. Ltd., Pfizer Inc., Shionogi \& Co., Ltd., and Mitsubishi Tanabe Pharma Co., and research funding from MSD K.K., Dainippon-Sumitomo Pharma Co. Ltd., Janssen Pharmaceutical K.K., Astellas Pharma Inc., Nippon Chemiphar Co. Ltd., Pfizer Inc., Mochida Pharmaceutical Co. Ltd., Eisai Co., Ltd. Meiji Seika Pharma Co., Ltd., Yoshitomiyakuhin Co., Shionogi \& Co., Ltd., and Mitsubishi Tanabe Pharma Co. Mitsukuni Murasaki declares personal fees from Astellas Pharma Inc., Meiji Seika Pharma Co., Ltd., Eli Lilly Japan, Eisai Co., Ltd., Otsuka Pharmaceutical Co., Ltd., Pfizer Inc., and Janssen Pharmaceutical K.K. Tsukasa Koyama declares personal fees from Astellas Pharma Inc., Eli Lilly Japan, Otsuka Pharmaceutical, and Mitsubishi Tanabe Pharma Co. Masahiro Takeuchi (takeuchim@pharm.kitasato-u.ac.jp) declares personal fees from Astellas Pharma Inc. Yuriko Shimizu, Eri Arita, Kentaro Kuroishi, Masahiro Takeuchi, and Shinya Kamei are employees of Astellas Pharma Inc.

\section{Author details}

'Department of Neuropsychiatry, Graduate School of Medical Sciences, Kyushu University, 3-1-1 Maidashi, Higashi-ku, Fukuoka 812-8582, Japan. ${ }^{2}$ Institute of CNS Pharmacology, 3-14-20 Sagamiohno, Minami-ku, Sagamihara, Kanagawa 252-0303, Japan. ${ }^{3}$ Ohyachi Hospital, Clinical Research Center, 5-7-10 Ohyachi-higashi, Atsubetsu-ku, Sapporo, Hokkaido 004-0041, Japan. ${ }^{4}$ Department of Clinical Medicine, School of Pharmacy, Kitasato University, 5-9-1 Shirokane, Minato-ku, Tokyo 108-8641, Japan. ${ }^{5}$ Japan/Asia Clinical Development 2, Astellas Pharma Inc.; 2-5-1 Nihonbashi-Honcho,

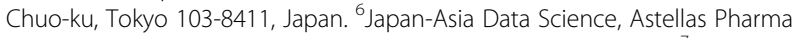
Inc, 2-5-1 Nihonbashi-Honcho, Chuo-ku, Tokyo 103-8411, Japan. ${ }^{7}$ Astellas Pharma Global Development, Inc, 1 Astellas Way, Northbrook, IL 60062, USA.

Received: 31 July 2018 Accepted: 13 June 2019

Published online: 26 June 2019

\section{References}

1. American Psychiatric Association. Bipolar and related disorders. In: Diagnostic and statistical manual of mental disorders. 5th ed; 2013.

2. Merikangas KR, Jin R, He JP, Kessler RC, Lee S, Sampson NA, Viana MC, Andrade LH, Hu C, Karam EG, et al. Prevalence and correlates of bipolar spectrum disorder in the world mental health survey initiative. Arch Gen Psychiatry. 2011;68(3):241-51.

3. Goodwin GM, Haddad PM, Ferrier IN, Aronson JK, Barnes T, Cipriani A, Coghill DR, Fazel S, Geddes JR, Grunze H, et al. Evidence-based guidelines for treating bipolar disorder: revised third edition recommendations from the British Association for Psychopharmacology. J Psychopharmacol. 2016;30:495-553.

4. Grunze H, Vieta E, Goodwin GM, Bowden C, Licht RW, Möller HJ, Kasper S. WFSBP task force on treatment guidelines for bipolar disorders. The world Federation of Societies of biological psychiatry (WFSBP) guidelines for the biological treatment of bipolar disorders: update 2010 on the treatment of acute bipolar depression. World J Biol Psychiatry. 2010;11:81-109.

5. Kanba S, Kato T, Terao T, Yamada K. Committee for Treatment Guidelines of mood disorders. JSoMD guideline for treatment of bipolar disorder by the Japanese Society of Mood Disorders, 2012. Psychiatry Clin Neurosci. 2013;67: 285-300.

6. Yatham LN, Kennedy SH, Parikh SV, Schaffer A, Beaulieu S, Alda M, O'Donovan C, Macqueen G, Mclntyre RS, Sharma V, et al. Canadian network for mood and anxiety treatments (CANMAT) and International Society for Bipolar Disorders (ISBD) collaborative update of CANMAT guidelines for the management of patients with bipolar disorder: update 2013. Bipolar Disord. 2013;15:1-44

7. Calabrese JR, Keck PE Jr, Macfadden W, Minkwitz M, Ketter TA, Weisler RH, Cutler AJ, McCoy R, Wilson E, Mullen J. A randomized, double-blind, placebo-controlled trial of quetiapine in the treatment of bipolar I or II depression. Am J Psychiatry. 2005;162(7):1351-60.

8. Thase ME, Macfadden W, Weisler RH, Chang W, Paulsson B, Khan A, Calabrese JR, Group BIS. Efficacy of quetiapine monotherapy in bipolar I and II depression: a double-blind, placebo-controlled study (the BOLDER II study). J Clin Psychopharmacol. 2006;26(6):600-9.

9. Suppes T, Datto C, Minkwitz M, Nordenhem A, Walker C, Darko D. Effectiveness of the extended release formulation of quetiapine as monotherapy for the treatment of acute bipolar depression. J Affect Disord. 2010;121(1-2):106-15. 
10. Murasaki M, Koyama T, Kanba S, Takeuchi M, Shimizu Y, Arita E, Kuroishi K, Takeuchi M, Kamei S. Multi-center, randomized, double-blind, placebocontrolled study of quetiapine extended-release formulation in Japanese patients with bipolar depression. Psychopharmacology. 2018;235(10):2859-69.

11. Judd LL, Akiskal HS, Schettler PJ, Coryell W, Endicott J, Maser JD, Solomon DA, Leon AC, Keller MB. A prospective investigation of the natural history of the long-term weekly symptomatic status of bipolar II disorder. Arch Gen Psychiatry. 2003;60(3):261-9.

12. Judd LL, Akiskal HS, Schettler PJ, Endicott J, Maser J, Solomon DA, Leon AC, Rice JA, Keller MB. The long-term natural history of the weekly symptomatic status of bipolar I disorder. Arch Gen Psychiatry. 2002;59(6):530-7.

13. Young AH, McElroy SL, Olausson B, Paulsson B, Embolden I. Embolden II investigators. A randomised, placebo-controlled 52-week trial of continued quetiapine treatment in recently depressed patients with bipolar I and bipolar II disorder. World J Biol Psychiatry. 2014;15(2):96-112.

14. American Psychiatric Association. Diagnostic and statistical manual of mental disorders (4th ed., text rev.). Washington, DC: American Psychiatric Association Publishing; 2000.

15. Spearing MK, Post RM, Leverich GS, Brandt D, Nolen W. Modification of the clinical global impressions (CGI) scale for use in bipolar illness (BP): the CGIBP. Psychiatry Res. 1997;73(3):159-71.

16. International Conference on Harmonisation of Technical Requirements for Registration of Pharmaceuticals for Human Use. ICH harmonised tripartite guideline: the extent of population exposure to assess clinical safety for drugs intended for long-term treatment of non-life-threatening conditions-E1. http://www.ich.org/fileadmin/Public_Web_Site/ICH_Products/Guidelines/ Efficacy/E1/Step4/E1_Guideline.pdf (Accessed June 19, 2018).

17. McElroy SL, Weisler RH, Chang W, Olausson B, Paulsson B, Brecher M, Agambaram V, Merideth C, Nordenhem A, Young AH, et al. A double-blind, placebo-controlled study of quetiapine and paroxetine as monotherapy in adults with bipolar depression (EMBOLDEN II). J Clin Psychiatry. 2010;71(2):163-74.

18. Young AH, McElroy SL, Bauer M, Philips N, Chang W, Olausson B, Paulsson B, Brecher M, Investigators El. A double-blind, placebo-controlled study of quetiapine and lithium monotherapy in adults in the acute phase of bipolar depression (EMBOLDEN I). J Clin Psychiatry. 2010;71(2):150-62.

19. Nashed MG, Restivo MR, Taylor VH. Olanzapine-induced weight gain in patients with Bipolar I Disorder: A meta-Analysis. Prim Care Companion CNS Disord. 2011;13(6). https://doi.org/10.4088/PCC.11 r01174.

20. De Hert M, Yu W, Detraux J, Sweers K, van Winkel R, Correll CU. Body weight and metabolic adverse effects of asenapine, iloperidone, lurasidone and paliperidone in the treatment of schizophrenia and bipolar disorder: a systematic review and exploratory meta-analysis. CNS Drugs. 2012;26(9):733-59.

21. Correll CU, Detraux J, De Lepeleire J, De Hert M. Effects of antipsychotics, antidepressants and mood stabilizers on risk for physical diseases in people with schizophrenia, depression and bipolar disorder. World Psychiatry. 2015; 14(2):119-36.

22. McLaren KD, Marangell LB. Special considerations in the treatment of patients with bipolar disorder and medical co-morbidities. Ann Gen Hosp Psychiatry. 2004;3:7.

23. La Torre D, Falorni A. Pharmacological causes of hyperprolactinemia. Ther Clin Risk Manag. 2007;3(5):929-51.

24. Kapur S, Zipursky R, Jones C, Shammi CS, Remington G, Seeman P. A positron emission tomography study of quetiapine in schizophrenia. Arch Gen Psychiatry. 2000;57(6):553-9.

25. Atmaca M, Kuloglu M, Tezcan E, Canatan H, Gecici O. Quetiapine is not associated with increase in prolactin secretion in contrast to haloperidol. Arch Med Res. 2002;33(6):562-5.

26. Gao K, Kemp DE, Ganocy SJ, Gajwani P, Xia G, Calabrese JR. Antipsychoticinduced extrapyramidal side effects in bipolar disorder and schizophrenia. J Clin Psychopharmacol. 2008;28(2):203-9.

27. Correll CU, Leucht S, Kane JM. Lower risk for tardive dyskinesia associated with second-generation antipsychotics: a systematic review of 1-year studies. Am J Psychiatry. 2004;161(3):414-25.

28. Viktorin A, Lichtenstein P, Thase ME, Larsson H, Lundholm C, Magnusson PK, Landen M. The risk of switch to mania in patients with bipolar disorder during treatment with an antidepressant alone and in combination with a mood stabilizer. Am J Psychiatry. 2014;171(10):1067-73.

\section{Publisher's Note}

Springer Nature remains neutral with regard to jurisdictional claims in published maps and institutional affiliations.

\section{Ready to submit your research? Choose BMC and benefit from}

- fast, convenient online submission

- thorough peer review by experienced researchers in your field

- rapid publication on acceptance

- support for research data, including large and complex data types

- gold Open Access which fosters wider collaboration and increased citations

- maximum visibility for your research: over $100 \mathrm{M}$ website views per year

At BMC, research is always in progress.

Learn more biomedcentral.com/submissions 